\title{
Design and Development of Novel Floating In Situ Gel of Amoxicillin for the Treatment of Peptic Ulcer Disease Caused by Helicobacter pylori
}

\author{
Mukesh S Patel ${ }^{1 *}$, Alpesh D Patel ${ }^{1}$, Nidhi R Doshi ${ }^{2}$ and Govind Vyas ${ }^{3}$ \\ ${ }^{1}$ Department of Pharmaceutics, Shri B.M. Shah College of Pharmaceutical \\ Education and Research, Gujarat, India \\ ${ }^{2}$ Research Scholar, Gujarat Technological University, Ahmedabad, Gujarat, India \\ ${ }^{3}$ Director, Research and Development, Invahealth. Inc Cranberry, NJ, USA \\ *Corresponding Author: Mukesh S Patel, Department of Pharmaceutics, Shri B.M. \\ Shah College of Pharmaceutical Education and Research, Gujarat, India.
}

Received: August 02, 2021

Published: August 28, 2021

(C) All rights are reserved by Mukesh S Patel., et al.

\begin{abstract}
The purpose of this work was to prepare a novel intragastric flotation system for controlled administration of amoxicillin for the treatment of peptic ulcers. By preparing controlled release floating in situ of amoxicillin reduce dosing frequency, better patient compliance, improve bioavailability of drug and minimize side effects. Large doses of amoxicillin (750 -1000 mg) can be easily provided in liquid dosage form, which is difficult to integrate into floating tablets. Natural Polymer-based floating gelation system was prepared by dissolving different concentrations of xanthan gum and guar gum in deionized water, then drug (Amoxicillin) and calcium carbonate were added. Fourier transform infrared spectroscopy was used to confirm the presence of interactions between drugs and excipients. $3^{2}$ experimental designs were used for optimization of formulation. The amount of gellan gum (X1) and calcium chloride (X2) were chosen as independent variables. The amount of drug released after 3 hours (Q3) and 6 hours (Q6) and 9 hours (Q9), the viscosity and the floating delay time of the liquid formulation were selected as dependent variables. Floating In-situ gels have been studied for their viscosity, in vitro buoyancy and drug release. The optimized formulation F6 provided sustained in vitro release of drug over an extended period of time up to $12 \mathrm{hrs}$. The drug release from gel structure follows a zero order release. As per the result and discussion the batch F6 is optimized batch which contain drug release $95.78 \%$ up to $12 \mathrm{hr}, 67.12 \%$ swelling index and show the maximum similarity factor 65.09. FIIR studies showed that there were no interaction between drug and polymer. The stability studies revealed that there were no significant changes in the dependable parameters of the formulation. It is clearly indicates that the optimize formulation were stable for 3 months. In nutshell, we can conclude that the formulated floating in situ gel were successfully formulated for the treatment of the of Peptic Ulcer Disease Caused By Helicobacter pylori.
\end{abstract}

Keywords: In Situ Gel; Amoxicillin; Floating Drug Delivery; Gastric Residence Time; Controlled Delivery

\section{Abbreviation}

GET: Gastric Emptying Time; GIT: Gastro Intestinal Tract; GRT: Gastro retention Time; f2: Similarity; f1: Dissimilarity; DF: Degree of Freedom; R: Reduced Model; FM: Full Model; ANOVA: Analysis of Variance

\section{Introduction}

Oral administration of drug is most preferred route of administration for due to its convenient administration, patient compliance, and flexibility in the formulations. This is partly due to the fact that the gastrointestinal tract offers a wide range of flexibility 
in dosage form design than other routes. Oral drug delivery system is suitable and ideal for the systematic circulation. The average residence time of formulations in the stomach depends on the type of dosage form. Tablets, pellets, capsules and solutions have an average residence time of $2.7 \pm 1.5$ hours, $1.2 \pm 1.3$ hours, 0.8 \pm 1.2 hours and $0.3 \pm 0.07$ hours respectively in the fed state. The effective duration of release from non-retentive controlled release delivery systems such as oral matrix or osmotic systems cannot extend beyond normal gastrointestinal (GI) transit time, and so is unpredictable and limited to around 12 hours maximum [1-6].

The drug is readily absorbed from the GIT and has a short halflife and is rapidly eliminated from the systemic circulation. Routine administrations of 2 of these drugs are required to achieve adequate therapeutic activity. To avoid this limitation, the development of oral sustained-release controlled-release formulations is an attempt to release the drug slowly in the GIT and maintain an effective concentration of the drug in the system for a long time. After oral administration, such drug will be retained in the stomach and will release the drug in a controlled manner, so that drug can be continuously delivered to its absorption sites in GIT. These drug delivery systems mainly suffer from two disadvantages: short gastric retention time (GRT) and unpredictable short gastric emptying time (GET), which can lead to release drug is not completely recovered from its dosage form in the area of absorption stomach or upper part of small intestine) resulting in a decrease in the effectiveness of the administered dose. In the orally administered controlled-release formulation specifically for site, it was desirable to achieve an extended gastric residence time by drug delivery $[3,4]$.

Prolonging gastric residence time improves bioavailability, increases drug release time, reduces drug waste and improves solubility of poorly soluble drugs in high pH environments. Prolonged gastric hypotensive period GRT) in the stomach may also be beneficial for local activity in the upper part of the GIT e.g. peptic ulcers etc. [7-9]. Gastro retention dosage forms can remain in the stomach for long periods of time and thus significantly prolongs the GRT of drugs. Over the past decades, several methods of gastric maintenance drug delivery have been designed and developed, including: Swelling or expanding systems, Bioadhesive system, floating drug delivery system, Magnetic systems, High density system and other delayed gastric emptying devices [10-15].

\section{Materials and Methods}

Amoxicillin was provided as a gift sample by Shreeji Pharma International, Vadodara, India. Gellan gum was purchased by Chem- dyes Corporation, Rajkot. All other ingredients were of analytical grade.

\section{Preparation of floating in situ gel}

Gellan gum solution was prepared in deionized water with sodium citrate. Xanthan gum were added in gellan gum solution and heat at $40{ }^{\circ} \mathrm{C}$ stirred for 30 min on magnetic stirrer. In another beaker add $30 \mathrm{ml}$ of deionized water and mixed with Calcium carbonate, Calcium chloride and stir on magnetic stirrer for $30 \mathrm{~min}$. mixed both the sample and add API and stir for $30 \mathrm{~min}$ [16-27]. Add required quantity of preservatives. Make up volume with deionized water, which is shown in table 3 .

\section{Optimization of variable using factorial design}

A $3^{2}$ randomized full factorial design was used in the present study [16]. In this design, 2 factors were evaluated, each at 3 levels and experimental trials were performed for all possible combinations. The concentration of gellan gum (X1) and concentration of calcium chloride (X2) were chosen as independent variables in $3^{2}$ full factorial design, while floating lag time, Q3, Q6, Q9 (\% drug release after 3, 6, and 9 hours respectively) and viscosity were taken as dependent variables. The formulation layout for the factorial design batches (F1-F9) are shown in table 1-3.

\begin{tabular}{|l|c|c|}
\hline Level & $\begin{array}{c}\text { Concentration of Gellan } \\
\text { gum (X1) }\end{array}$ & $\begin{array}{c}\text { Concentration of Calcium } \\
\text { chloride (X2) }\end{array}$ \\
\hline-1 & $0.3 \%$ & $0.1 \%$ \\
\hline 0 & $0.4 \%$ & $0.2 \%$ \\
\hline+1 & $0.5 \%$ & $0.3 \%$ \\
\hline
\end{tabular}

Table 1: Coding of Variables.

\begin{tabular}{|l|c|c|}
\hline Formulation Code & X1 & X2 \\
\hline F1 & -1 & -1 \\
\hline F2 & -1 & 0 \\
\hline F3 & -1 & +1 \\
\hline F4 & 0 & -1 \\
\hline F5 & 0 & 0 \\
\hline F6 & 0 & +1 \\
\hline F7 & +1 & -1 \\
\hline F8 & +1 & 0 \\
\hline F9 & +1 & +1 \\
\hline
\end{tabular}

Table 2: Coding Layout of full factorial batches. 


\begin{tabular}{|l|c|c|c|c|c|c|c|c|c|}
\hline \multirow{2}{*}{ Ingredient (\%w/v) } & \multicolumn{7}{|c|}{ Formulation batch code } \\
\cline { 2 - 10 } & F1 & F2 & F3 & F4 & F5 & F6 & F7 & F8 & F9 \\
\hline Amoxicillin & 7.5 & 7.5 & 7.5 & 7.5 & 7.5 & 7.5 & 7.5 & 7.5 & 7.5 \\
\hline Gellan gum & 0.3 & 0.3 & 0.3 & 0.4 & 0.4 & 0.4 & 0.5 & 0.5 & 0.5 \\
\hline Xanthan gum & 0.5 & 0.5 & 0.5 & 0.5 & 0.5 & 0.5 & 0.5 & 0.5 & 0.5 \\
\hline Sodium citrate & 0.6 & 0.6 & 0.6 & 0.6 & 0.6 & 0.6 & 0.6 & 0.6 & 0.6 \\
\hline CaCl2 & 0.10 & 0.20 & 0.30 & 0.10 & 0.20 & 0.30 & 0.10 & 0.20 & 0.30 \\
\hline CaCO3 & 0.5 & 0.5 & 0.5 & 0.5 & 0.5 & 0.5 & 0.5 & 0.5 & 0.5 \\
\hline Methyl paraben & 0.2 & 0.2 & 0.2 & 0.2 & 0.2 & 0.2 & 0.2 & 0.2 & 0.2 \\
\hline Distilled water (upto $100 \mathrm{ml})$ & 100 & 100 & 100 & 100 & 100 & 100 & 100 & 100 & 100 \\
\hline
\end{tabular}

Table 3: Formulation layout of full factorial design.

\section{In vitro drug release study}

Using a USP device (model TDL08L, Electrolab, Mumbai, India) at $37 \pm 0.5^{\circ} \mathrm{C}, 500 \mathrm{ml}$ of $0.1 \mathrm{~N} \mathrm{HCl}$ was used to mount the paddle (50 revolutions / $\mathrm{min}$ ) to determine the in vitro release rate of amoxicillin from in situ sustained release gel as a dissolution medium. The speed is slow enough to prevent it from breaking down into a gelled formulation and to maintain the mild agitation conditions believed to be removed from the body. At predetermined time intervals, $5 \mathrm{ml}$ samples were taken, passed through Whatman filter paper, diluted and analyzed at $272 \mathrm{~nm}$ using a Shimadzu UV 1800 double beam spectrophotometer (Shimadzu, Kyoto, Japan). The percent cumulative drug release (CPR) is calculated using the equation obtained from the calibration curve [21,24-27].

\section{Appearance of gel}

Appearance of floating in situ gel was determined by visual inspection.

\section{Measurement of viscosity of in situ gelling solution}

The viscosity of the prepared solution was measured with a Brookfield viscometer (Brookfield Engineering Labs Inc. Middleboro, MA 02346 U.S.A.). Samples (100 ml) were sheared at room temperature using an appropriate spindle at a speed of $100 \mathrm{rpm}$. Viscosity measurements of each sample were repeated 3 times and each measurement took about 30 seconds [19,20,25].

\section{In vitro floating study}

The floating study of the gelling solution in situ was performed in $500 \mathrm{ml}$ of $0.1 \mathrm{~N} \mathrm{HCl}$ (pH 1.2) in the dissolution vessel. Measure the time required to float to the surface after adding the solution (float lag time) and the total float time [21].

\section{Content uniformity}

$10 \mathrm{ml}$ of liquid solution (containing $750 \mathrm{mg}$ Amoxicillin) add to the $30 \mathrm{ml}$ of $0.1 \mathrm{~N} \mathrm{HCl}$ for $30 \mathrm{~min}$ on magnetic stirrer. After 30 min, sample put on in sonicator for $30 \mathrm{~min}$ until clear solution and make up volume up to $100 \mathrm{ml}$. Take $1 \mathrm{ml}$ and dilute up to $100 \mathrm{ml}$ and measured the absorption at $272 \mathrm{~nm}$ in UV spectrophotometer $[18,26]$.

\section{pH measurement}

The $\mathrm{pH}$ of the prepared liquid formulation was measured with a Welltonix digital $\mathrm{pH}$ meter. To measure the $\mathrm{pH}$, first stabilize the $\mathrm{pH}$ of the $\mathrm{pH}$ meter with twice distilled water, after conditioning; calibrate the $\mathrm{pH}$ meter with $0.1 \mathrm{~N} \mathrm{HCl}$ and phosphate buffer $\mathrm{pH} 6.8$. Finally, check the $\mathrm{pH}$ of all the batches [24,27].

\section{Gel strength determination}

A $50 \mathrm{~g}$ sample of Floating-In-situ gel was placed in a $100 \mathrm{ml}$ graduated cylinder. A mass of $35 \mathrm{~g}$ is deposited on the lubricated sample. The strength of the gel, which is an index of the viscosity of a gel floating in situ at physiological temperature, was determined by the time in seconds required by weight to penetrate $5 \mathrm{~cm}$ into the gel [22-27].

Swelling index

The gel swelling index of the selected formulation is determined by a simple method. In this study, an in-situ gel formed in $40 \mathrm{ml}$ of 
$0.1 \mathrm{~N} \mathrm{HCl}(\mathrm{pH} 1.2)$ was used. Separate the $0.1 \mathrm{~N} \mathrm{HCl}$ gel fraction from each formulation, and remove the excess $\mathrm{HCl}$ solution with paper towels. Weigh the initial weight of the gel, add $50 \mathrm{ml}$ of distilled water to the gel, pour out the water after 12 hours, record the weight of the gel, calculate and report the weight difference $[17,19]$.

Drug-polymer compatibility studies

Drug-polymer compatibility studies were spectrophotometer (FTIR 8400S Spectrophotometer Shimadzu, Japan) by KBr pellet method. FTIR of Amoxicillin and excipients recorded using $\mathrm{KBr}$ mixing method. Drug excipients associations assume an imperative part in release drugs from the formulation. The Amoxicillin and excipients beforehand ground and blended with $\mathrm{KBr}$, and infrared translucent matrix, at 1:10 (sample: $\mathrm{KBr}$ ) ratio. The $\mathrm{KBr}$ discs were set up by packing the powders. The samples were scanned between ranges of 400-4000 cm-1 [16,19,23].

\section{Stability studies}

Stability testing of drug products begins as a part of drug discovery and ends with the demise of the compound or commercial product. The stability studies were performed on the most satisfactory formulation as per ICH guidelines Q1C. The optimized formulation (F5) sealed in vial with rubber cap and kept in humidity chamber maintained $40 \pm^{\circ} \mathrm{C} / 75 \pm 5 \% \mathrm{RH}$ for 3 month. At the end of studies, samples were analyzed for the drug content, in vitro drug release, $\mathrm{pH}$, and viscosity. Comparison of both the batches was carried out using similarity factor (f2) and dissimilarity factor (f1) $[16,18]$.

\section{Result and Discussion}

Drug-polymer compatibility studies

Table 4 and figure 1 clearly indicates that the level of pure drug and formulation having same peak in FTIR spectra that revealed that there was no physical and chemical interaction between drug and Excipients in the formulation.

\begin{tabular}{|l|l|l|}
\hline \multirow{2}{*}{$\begin{array}{l}\text { Functional } \\
\text { Group }\end{array}$} & \multicolumn{2}{|l|}{ Frequency } \\
\cline { 2 - 3 } & Pure Drug & Formulation \\
\hline C=O & $1774 \mathrm{~cm}^{-1}$ & $1774 \mathrm{~cm}^{-1}$ \\
\hline C-H & $3037 \mathrm{~cm}^{-1}$ & $2970 \mathrm{~cm}^{-1}$ \\
\hline $\mathrm{N}-\mathrm{H}$ & $1249 \mathrm{~cm}^{-1}$ & $1248 \mathrm{~cm}^{-1}$ \\
\hline C-O & $1313 \mathrm{~cm}^{-1}$ & $1327 \mathrm{~cm}^{-1}$ \\
\hline C=C & $1486 \mathrm{~cm}^{-1}$ & $1486 \mathrm{~cm}^{-1}$ \\
\hline
\end{tabular}

Table 4: FTIR peak of pure drug and formulation.

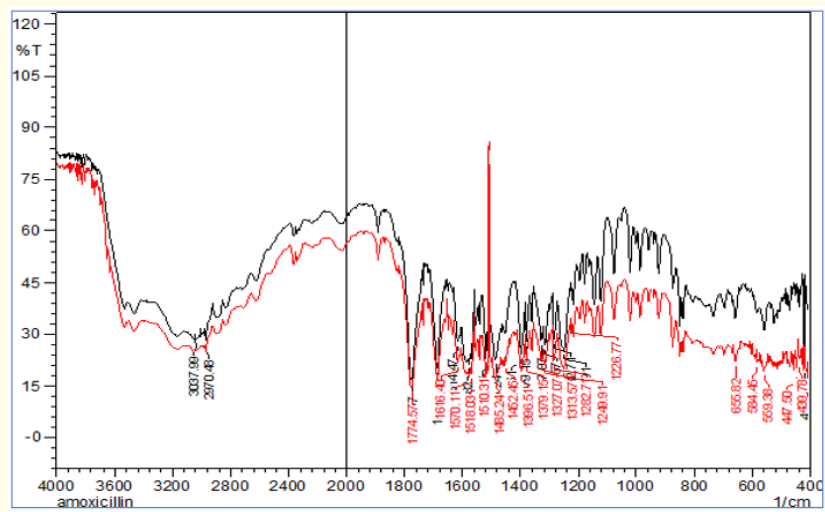

Figure 1: FTIR of Amoxicillin + Formulation.

Physical appearance

As the concentration of Gellan gum and Calcium Chloride increase, stiffness of the gel network also increased due to gelling nature of Gellan gum and hydrophobicity of $\mathrm{Ca}^{+2}$ ion. Physical appearance of gel can be determined by visual Inspection. Results are shown in figure 4.

\section{Viscosity of in situ gelling solution}

The rheological properties of the solutions are of importance in view of their proposed oral administration. The two main prerequisites of in situ gelling systems are optimum viscosity and gelling capacity (speed and extent of gelation). The formulation should have an optimum viscosity that will allow easy swallowing as a liquid which is depicted in table 5. An increase concentration of gellan gum with increasing the number of particle dispersed, thus contributing to the increased the viscosity and also show that as speed increased, viscosity of formulation decreased as shown in table 6 [24-27].

\section{pH of formulation}

$\mathrm{pH}$ of the all formulation is weak basic side and near about the neutral $\mathrm{pH}$, As per the stability point of view the formulation was more stable at higher $\mathrm{pH}$ (more than 8. pH of the stomach is strongly acidic ( $\mathrm{pH}$ 1.2), so dissociation of into the stomach due to weak basic and strong acid mechanism. Due to high amount of dissociation create ionic exchange of particular ion and formation of gel. The gellan gum based in situ gelling liquid formulation containing calcium ion in complexed from gets converted into gel when reaches to acidic environment of stomach and made the formulation to float for prolong period of time up to $12 \mathrm{hrs}$ [24,25]. Results of the all formulations are displayed in table 5. 


\begin{tabular}{|l|c|c|c|c|c|}
\hline $\begin{array}{l}\text { Batch } \\
\text { Code }\end{array}$ & pH & $\begin{array}{c}\text { Gel } \\
\text { Strength(Sec) }\end{array}$ & $\begin{array}{c}\text { Viscosity } \\
\text { (Cps) }\end{array}$ & $\begin{array}{c}\text { Swelling } \\
\text { Index(\%) }\end{array}$ & $\begin{array}{c}\text { Drug } \\
\text { Content(\%) }\end{array}$ \\
\hline F1 & 8.20 & $20.32 \pm 1.50$ & 200 & $28.15 \pm 1.50$ & $100.01 \pm 1.78$ \\
\hline F2 & 8.04 & $25.62 \pm 2.45$ & 240 & $43.50 \pm 1.35$ & $98.63 \pm 2.29$ \\
\hline F3 & 8.16 & $31.45 \pm 1.22$ & 300 & $76.34 \pm 2.25$ & $99.54 \pm 3.01$ \\
\hline F4 & 8.32 & $32.56 \pm 1.56$ & 380 & $36.60 \pm 1.86$ & $97.95 \pm 1.56$ \\
\hline F5 & 8.10 & $40.34 \pm 0.89$ & 396 & $49.10 \pm 1.36$ & $97.72 \pm 2.25$ \\
\hline F6 & 8.22 & $49.54 \pm 2.21$ & 420 & $67.12 \pm 1.60$ & $98.18 \pm 1.89$ \\
\hline F7 & 8.32 & $55.20 \pm 1.87$ & 460 & $24.26 \pm 1.49$ & $98.63 \pm 1.56$ \\
\hline F8 & 8.20 & $60.75 \pm 1.35$ & 480 & $50.12 \pm 2.35$ & $97.27 \pm 1.43$ \\
\hline F9 & 8.20 & $72.35 \pm 1.45$ & 560 & $84.50 \pm 2.39$ & $96.59 \pm 2.20$ \\
\hline
\end{tabular}

Table 5: Evaluation parameter of Batch F1-F9.

\begin{tabular}{|l|c|c|}
\hline \multirow{2}{*}{ Batch Code } & \multicolumn{2}{|c|}{ Viscosity (Cps) } \\
\cline { 2 - 3 } & Speed 6 & Speed 12 \\
\hline F1 & 200 & 190 \\
\hline F2 & 240 & 225 \\
\hline F3 & 300 & 275 \\
\hline F4 & 380 & 360 \\
\hline F5 & 396 & 380 \\
\hline F6 & 420 & 410 \\
\hline F7 & 460 & 440 \\
\hline F8 & 480 & 465 \\
\hline F9 & 560 & 530 \\
\hline
\end{tabular}

Table 6: Effect of speed on viscosity formulation.

\section{Swelling index}

Release of the drug from a polymeric matrix depends on the amount of water associated with the system. The release of the drug may improve the penetration of water into the matrix and simultaneous release of the drug via diffusion or dissolution as govern by fick's law, swelling index of gel formulation mainly depend on the polymeric concentration. Result of swelling index is depicted in table 5 as the concentration of polymer increase the swelling index will also be increased. In the batch F1 having low concentration of polymer showed $28.15 \%$ swelling index and Batch F9 contain higher amount of polymer show $84.50 \%$ swelling index, however batch F6 having a medium concentration of polymer exhibited a $67.12 \%$ swelling index [24-27].

\section{Drug content}

The percentage drug content of all the prepared in situ gel for- mulations were measured by using UV spectrophotometer and it was found in acceptable range of $90-100 \%$ as per the standard compendium ${ }^{24}$ which is exhibited in table 5 .

In vitro drug release study

In vitro drug release profile of full factorial design bathes, it can be concluded that as the concentration of Gellan Gum and Calcium chloride increase, drug release from gel network decrease in F1-F9 batches were exhibited in figure 2. Due to hydrophilic and swelling properties of gellan gum, Xanthan gum and Hydrophobic nature of $\mathrm{Ca}^{+2}$ ion which retard the water penetration to the gel network and to from a rigid network of the gel so decrease a release rate of Amoxicillin from gel network and prolong drug release up to 12 hrs. In the batch F1 having low concentration of polymer, it showed the drug release $95.13 \%$ up to $8 \mathrm{hr}$ whereas F9 batch containing highest polymer concentration that showed the $87.63 \%$ drug release within $12 \mathrm{hrs}$, but the batch F6 exhibited the more uniformity in drug release and desirable for sustain release effect so, it was showed the drug release $95.78 \%$ within 12 hrs [26,27].

\section{Measurement of gel strength}

As per the result (Table 5) as the concentration of the gellan gum and calcium chloride is increased so, increase the gelling strength of the floating in situ gel. Gel strength of formulated gels also increased with stiffness which extends the drug release for longer period of time. Gel strength is indicative of the tensile strength of the gelled mass. It signifies the ability of the gelled mass to withstand the peristaltic movement in vivo. Formulation containing low amount of gellan gum formed very weak slimy gel. The degree of rigidness of the gel can thus be attributed to the concentration of the polymer and $\mathrm{Ca}^{+2}$ ions. 


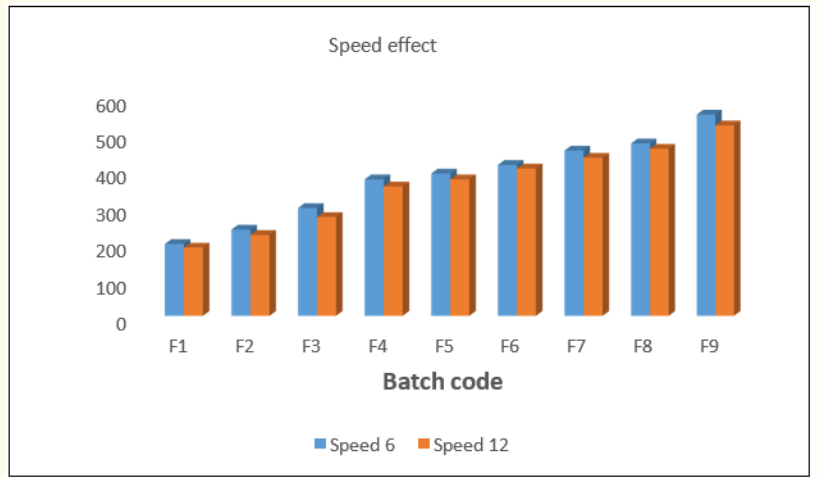

Figure 2: Comparison of Rheological profile of batch F1-F9.

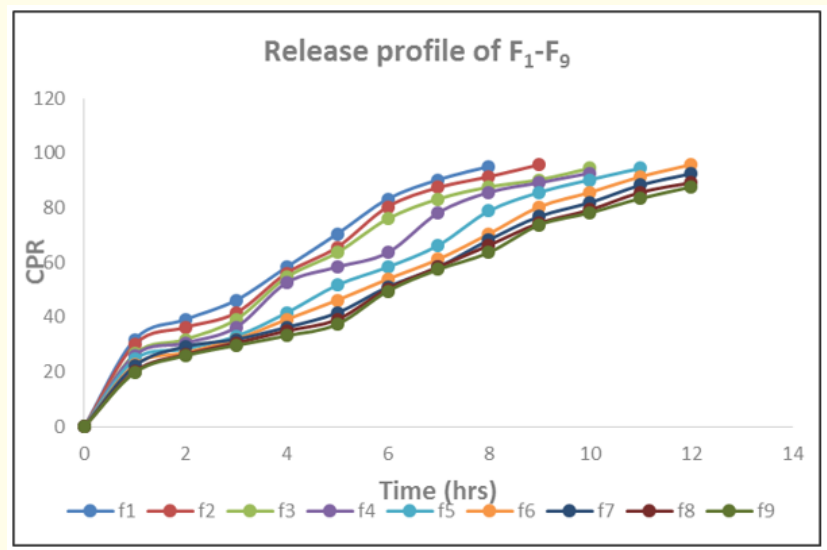

Figure 3: In vitro release profile for batches F1-F9.

Full and reduced model for floating lag time

The significance levels of the coefficients b1, b12, b11 and b22 were found to be $\mathrm{P}=0.380,0.238,1$ and 0.321 respectively, so there omitted from the full model to generate a reduced model. The results of statistical analysis are presented in table 7 . The coefficient b0 were found to be significant at $\mathrm{P}<0.05$, hence they were retained in the reduced model. The reduced model was tested in proportion to determine whether the coefficients b1, b12, b11 and b22 contribute significance information to the prediction of FLT. The results of model testing are shown in table 7 . The critical value of $F$ for $\alpha=0.05$ is equal to $9.27(\mathrm{df}=3,3)$. Since the calculated value ( $F$ $=0.2081)$ is less than critical value $(\mathrm{F}=9.27)$, it may be concluded that the interaction terms b1, b12, b11 and b22 do not contribute significantly to the prediction of FLT and can be omitted from the full model to generate the reduced model.

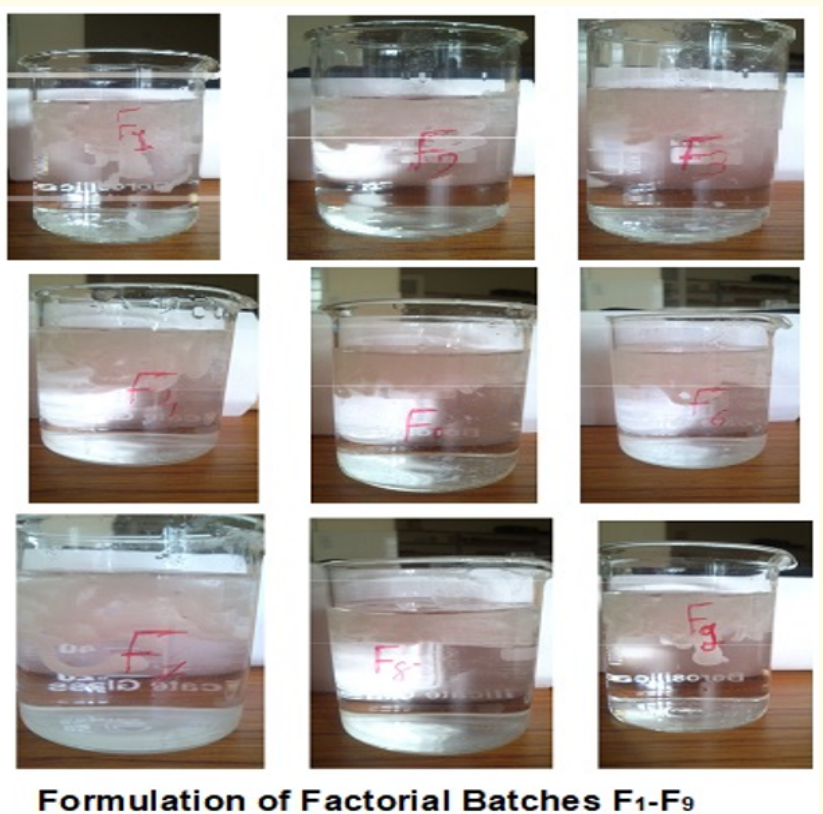

Figure 4: Physical Appearance of Floating in situ gel Formulations F1-F9 in $0.1 \mathrm{M} \mathrm{HCl}$.

\begin{tabular}{|l|l|l|l|l|l|l|}
\hline \multicolumn{7}{|l|}{ Viscosity (Cps) } \\
\hline Response & $\mathrm{b} 0$ & $\mathrm{~b} 1$ & $\mathrm{~b} 2$ & $\mathrm{~b} 12$ & $\mathrm{~b} 11$ & $\mathrm{~b} 22$ \\
\hline FM & 388.88 & 126.66 & 40.00 & -4.40 & -25.33 & 14.66 \\
\hline RM & 381.77 & 126.66 & 40.00 & - & - & - \\
\hline Floating Lag Time (sec) & $\mathrm{b} 1$ & $\mathrm{~b} 2$ & $\mathrm{~b} 12$ & $\mathrm{~b} 11$ & $\mathrm{~b} 22$ \\
\hline Response & $\mathrm{b} 0$ & $\mathrm{~b} 1$ & \\
\hline FM & 37.66 & 1.00 & -0.666 & 1.75 & 4.71 & 2.00 \\
\hline RM & 39.0 & 1.02 & -0.666 & - & - & - \\
\hline Q3 & \multicolumn{7}{|l|}{} \\
\hline Response & $\mathrm{b} 0$ & $\mathrm{~b} 1$ & $\mathrm{~b} 2$ & $\mathrm{~b} 12$ & $\mathrm{~b} 11$ & $\mathrm{~b} 22$ \\
\hline FM & 33.225 & -5.798 & -2.273 & 1.21 & 2.791 & 0.806 \\
\hline RM & 33.76 & - & -2.273 & 1.21 & 2.791 & - \\
\hline Q6 & \multicolumn{7}{|l|}{} \\
\hline Response & $\mathrm{b} 0$ & $\mathrm{~b} 1$ & $\mathrm{~b} 2$ & $\mathrm{~b} 12$ & $\mathrm{~b} 11$ & $\mathrm{~b} 22$ \\
\hline FM & 58.743 & -14.75 & -3.085 & 1.43 & 6.46 & -0.145 \\
\hline RM & 62.95 & -14.75 & -3.085 & - & 6.46 & - \\
\hline Q9 & 85.60 & -9.358 & -2.79 & - & - & - \\
\hline Response & $\mathrm{b} 0$ & $\mathrm{~b} 1$ & $\mathrm{~b} 2$ & $\mathrm{~b} 12$ & $\mathrm{~b} 11$ & $\mathrm{~b} 22$ \\
\hline FM & 85.75 & -9.358 & -2.79 & 0.442 & -0.695 & -1.03 \\
\hline RM & 85.60 & \\
\hline
\end{tabular}

Table 7: Results of regression analysis.

FM- Full Model; RM- Reduced Model. 


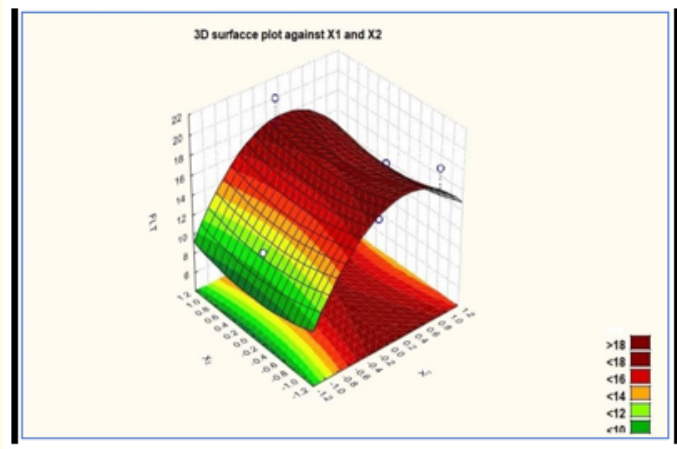

$5 \mathrm{~A}$

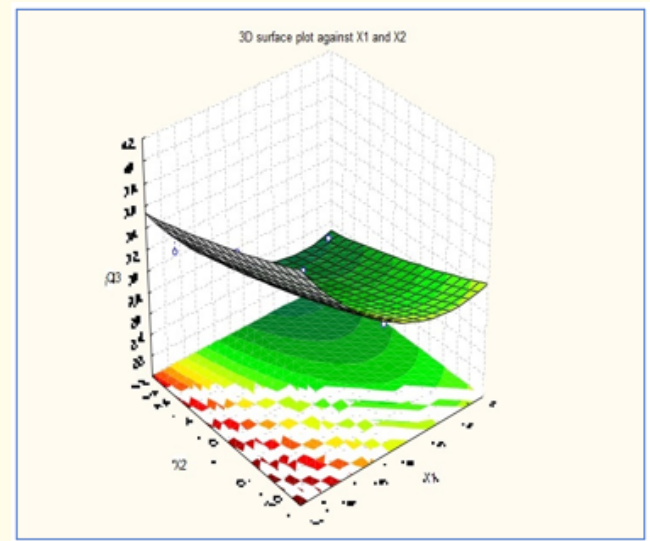

$5 \mathrm{C}$

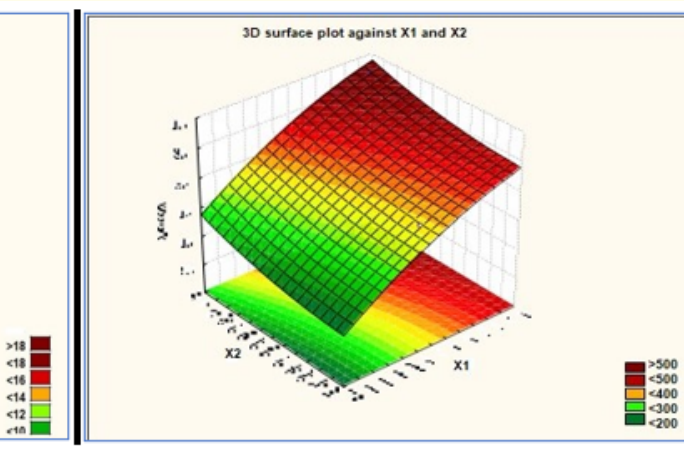

5B

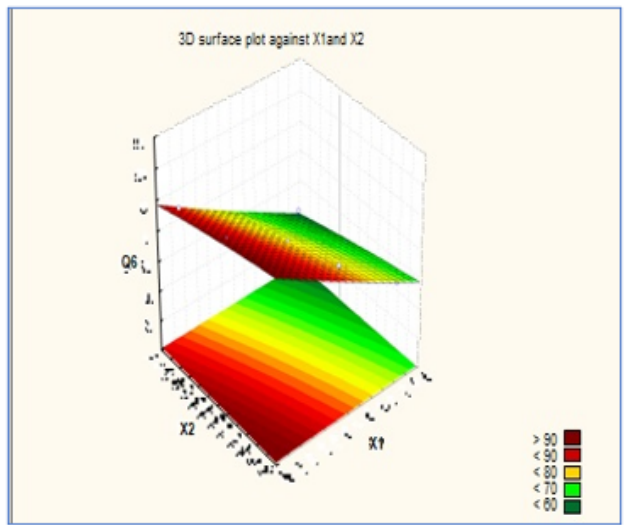

5D

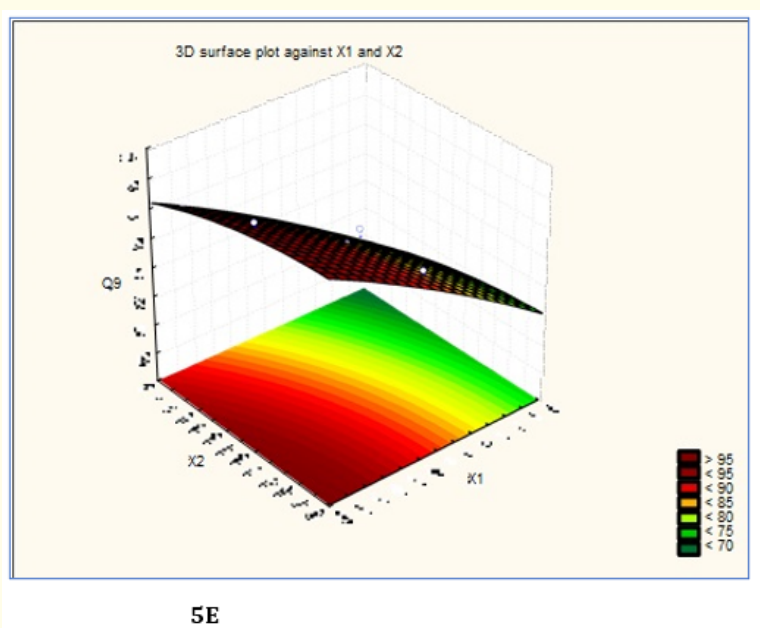

Figure 5: Response surface plot A). Floating time B). Viscosity C). Drug release at 3hrs (Q3) D). Drug release at 6 hrs (Q6) E) Drug release at 9 hrs (Q9). 
Full and reduced model for viscosity

The significance level of the coefficients b12, b11 and b22 was found to be respectively $\mathrm{P}=1,0.201$ and 0.414 , hence they were omitted from the full model to generate a reduced model. The results of Statistica analysis are shown in table 7. The coefficient b1, b2 was found to be significant at $\mathrm{P}<0.05$, hence they were retained in the reduced model. The reduced model was tested in proportion to determine whether the coefficient $\mathrm{b} 12, \mathrm{~b} 11$ and b22 contribute significant information to the prediction of viscosity. The result model testing is revealed in table 8. The critical value of $\mathrm{F}$ for $\alpha=$ 0.05 is equal to $9.27(\mathrm{df}=3,3)$. Since the calculated value $(\mathrm{F}=1.18)$ is less than critical value $(F=9.27)$, it may be concluded that the interaction terms b12, b11 and b22do not contribute significantly to the prediction of viscosity and can be omitted from the full model to generate the reduced model.

\begin{tabular}{|c|c|c|c|c|c|c|}
\hline \multicolumn{7}{|c|}{ Viscosity } \\
\hline & DF & SS & MS & $\mathbf{F}$ & $\mathbf{R}^{2}$ & \\
\hline \multicolumn{7}{|c|}{ Regression Analysis } \\
\hline FM & 5 & 107580.4 & 21516.09 & 44.60 & 0.986 & \multirow{5}{*}{$\begin{array}{l}F_{\text {cal }}=1.18 \\
\text { Ftable }=9.27 \\
(D F=3,3)\end{array}$} \\
\hline RM & 2 & 105866.7 & 52933.3 & 100.47 & 0.971 & \\
\hline \multicolumn{6}{|c|}{ Error } & \\
\hline FM & 3 & 1447.11 & 482.37 & & & \\
\hline $\mathrm{RM}$ & 6 & 3160.8 & 526.81 & & & \\
\hline \multicolumn{7}{|c|}{ Floating Lag Time } \\
\hline \multicolumn{7}{|c|}{ Regression } \\
\hline FM & 5 & 28.91 & 5.78 & 1.01 & 0.628 & \multirow{4}{*}{$\begin{array}{l}F_{\text {cal }}=0.20 \\
F_{\text {table }}=9.27 \\
(D F=3,3)\end{array}$} \\
\hline $\mathrm{RM}$ & 2 & 8.66 & 4.33 & 0.696 & 0.188 & \\
\hline \multicolumn{6}{|c|}{ Error } & \\
\hline \multirow[t]{2}{*}{ FM } & 3 & 17.08 & 5.69 & & & \\
\hline & 6 & 37.33 & 6.22 & & & \\
\hline \multicolumn{7}{|l|}{ Q3 } \\
\hline \multicolumn{6}{|c|}{ Regression } & \\
\hline FM & 5 & 255.47 & 51.09 & 425.42 & 0.998 & \multirow{5}{*}{$\begin{array}{l}\mathrm{F}_{\mathrm{cal}} \\
=3.61 \mathrm{Ft}- \\
\mathrm{able}=10.12 \\
(\mathrm{DF}=1,3)\end{array}$} \\
\hline RM & 4 & 254.17 & 63.54 & 0.429 & 0.205 & \\
\hline \multicolumn{6}{|c|}{ Error } & \\
\hline FM & 3 & 0.360 & 0.120 & & & \\
\hline RM & 4 & 1.66 & 0.415 & & & \\
\hline \multicolumn{7}{|l|}{ Q6 } \\
\hline \multicolumn{6}{|c|}{ Regression } & \\
\hline FM & 5 & 1454.75 & 290.95 & 89.23 & 0.993 & \multirow{5}{*}{$\begin{array}{l}\mathrm{F}_{\mathrm{cal}}=8.76 \\
\text { Ftable } \\
=9.55 \\
(\mathrm{DF}=2,3)\end{array}$} \\
\hline RM & 3 & 1369.04 & 456.34 & 23.89 & 0.934 & \\
\hline \multicolumn{6}{|c|}{ Error } & \\
\hline FM & 3 & 9.781 & 3.26 & & & \\
\hline RM & 5 & 95.49 & 19.09 & & & \\
\hline \multicolumn{7}{|l|}{ Q9 } \\
\hline \multicolumn{6}{|c|}{ Regression } & \\
\hline FM & 3 & 576.04 & 115.20 & 26.41 & 0.977 & \multirow{5}{*}{$\begin{array}{l}\mathrm{F}_{\text {cal }}=0.29 \\
\text { Ftable } \\
=9.27 \\
\mathrm{DF}=3,3)\end{array}$} \\
\hline RM & 2 & 572.175 & 286.08 & 10.12 & 0.971 & \\
\hline \multicolumn{6}{|c|}{ Error } & \\
\hline FM & 5 & 13.086 & 4.36 & & & \\
\hline RM & 6 & 16.95 & 2.82 & & & \\
\hline
\end{tabular}

Table 8: Results for ANOVA.

DF indicates the degree of freedom, SS: Sum of squares, MS: Mean of squares, R²: Regressioncoefficient, FM: Full model, RM: Reduced model, Q3, Q6, Q9 indicates percentage of drug released after 3, 6 and $9 \mathrm{hr}$ respectively. 
Full and reduced model for Q3

The significance level of the coefficient $\mathrm{b} 1$ was found to be respectively $\mathrm{P}=3.2$, hence they were omitted from the full model to generate a reduced model. The results of statistical analysis are exhibited in table 7. The coefficient b2, b12, b11 and b22 were found to be significant at $\mathrm{P}<0.05$, hence they were retained in the reduced model. The reduced model was tested in proportion to determine whether the coefficient b1 contribute significant information to the prediction of drug release at Q3. The result model testing are revealed in table 8 . The critical value of $F$ for $\alpha=0.05$ is equal to $10.12(\mathrm{df}=1,3)$. Since the calculated value $(\mathrm{F}=3.61)$ is less than critical value $(F=10.12)$, it may be concluded that the interaction terms b1 does not contribute significantly to the prediction of drug release at Q3 and can be omitted from the full model to generate the reduced model.

\section{Full and reduced model for Q6}

The significance level of the coefficient b12, b22 was found to be respectively $\mathrm{P}=0.211$ and 0.916 , hence they were omitted from the full model to generate a reduced model. The results of statistical analysis are shown in table 7. The coefficient b1, b2 and b11 were found to be significant at $\mathrm{P}<0.05$, hence they were retained in the reduced model. The reduced model was tested in proportion to determine whether the coefficient b12 and b22 contribute significant information to the prediction of drug release at Q6. The result model testing is displayed in table 8. The critical value of $\mathrm{F}$ for $\alpha=$ 0.05 is equal to $9.55(\mathrm{df}=2,3)$. Since the calculated value $(\mathrm{F}=8.76)$ is less than critical value ( $\mathrm{F}=9.55)$, it may be concluded that the interaction terms b12, b22 does not contribute significantly to the prediction of drug release at Q6 and can be omitted from the full model to generate the reduced model.

\section{Full and reduced model for $\mathbf{Q 9}$}

The significance level of the coefficient b12, b11 and b22 was found to be respectively $\mathrm{P}=0.700,0.670$ and 0.535 , hence they were omitted from the full model to generate a reduced model. The results of statistical analysis are presented in table 6 . The coefficient $\mathrm{b} 1, \mathrm{~b} 2$ was found to be significant at $\mathrm{P}<0.05$, hence they were retained in the reduced model. The reduced model was tested in proportion to determine whether the coefficient b12, b11 and b22 contribute significant information to the prediction of drug release at Q9. The result model testing are shown in table 7. The critical value of $\mathrm{F}$ for $\alpha=0.05$ is equal to 9.27 ( $\mathrm{df}=3,3$ ). Since the calculated value $(\mathrm{F}=0.295)$ is less than critical value $(\mathrm{F}=9.27)$, it may be concluded that the interaction terms b12, b11 and b22 does not contribute significantly to the prediction of drug release at Q9 and can be omitted from the full model to generate the reduced model.

\section{Kinetic modeling of dissolution data}

The kinetics of the dissolution data were well fitted to zero order, Higuchi model, and Krosemeyer-Peppas model as evident from regression coefficients as show in table. In case of the controlled or sustained release formulations, diffusion, swelling, and erosion are the three most important rate controlling mechanisms. Formulations containing swelling polymers show swelling as well as diffusion mechanism because the kinetic of swelling includes relaxation of polymer chains and diffusion of water, causing the polymer to swell and changing it from a glassy to rubbery state. The diffusion exponent $n$ is the indicative of the mechanism of drug release from the formulation. For a swellable cylindrical drug delivery system, the $n$ value of less than 0.5 is indicative of Fickian diffusion controlled drug release, $n$ value between 0.5 and 1.0 signifies anomalous (non-Fickian) transport; $n$ value of 1 indicates case II transport, and $n$ value greater than 1 indicates super case II transport. The value of diffusion exponent $n$ for all factorial formulations F1F9 is less than 0.5-1.0 (Table 8) significant anomalous (non-Fickian) transport drug release from the formulations.

Kinetic model Higuchi indicate that $\mathrm{R}^{2}$ value of $\mathrm{F} 1$ to $\mathrm{F} 9$ was between 0.972 to 0.976 that was near about 1.000 shown that drug release types was diffusion type from gel network and extend drug release for longer period of time. Kinetic model zero order indicating that $R^{2}$ value of $F 1$ to F9 was between 0.981 to 0.996 that near about 1.000 clearly mentioned that drug release from stiff gel networking was zero order drug release that not depends on concentration of drug. Kinetic model first order indicating that $\mathrm{R}^{2}$ value of F1 to F9 was between 0.971 to 0.988 that having less than zero order release $\mathrm{R}^{2}$ value, mentioned that drug release type was not first order release from gel network. Batch F6 having the better $\mathrm{R}^{2}$ value and diffusion exponent, drug release up to 12 hours that was desirable for study than other batch so, count as optimized batch.

Statistical analysis of floating time, viscosity, Q3, Q6 and Q9

Numerical analysis of the design evaluated utilizing enrolled 
Design Expert 8. The gotten data fitted in the design expert programming to examine various measurable boundaries. The examination model portraying the impact of multiple elements on RSM of yield factors like Floating time, viscosity, Q3 (\%), Q6 (5) and Q9 (\%) drug release in $9 \mathrm{~h}$. The critical evaluation chose the best preparation. The criterion for selecting the best trials depends on the highest drug discharge at $12 \mathrm{~h}$. 3-factor interaction model is considered for Y1, Y2, Y3 Y4, and Y4 in detail to demonstrate the Design space [20]. For Floating time the 3 -factor interactions discovered the best fit model, and the polynomial condition exhibits below:

$\mathrm{FLT}=37.66+1 \mathrm{X} 1-0.66 \mathrm{X} 2+1.75 \mathrm{X} 1 \mathrm{X} 2+4.71 \mathrm{X} 1 \mathrm{X} 1+2.0 \mathrm{X} 2 \mathrm{X}$ in 3D plot (Figure $5 \mathrm{~A})$.

It shows that positive signs of the $\mathrm{X} 1$ (concentration of gellan gum) and X2(concentration of calcium chloride) variables show that the Floating time (hr) is the upsurge to increment the X1 and $\mathrm{X} 2$. While considering the reaction term of Floating time (hr), the reaction surface plot demonstrates the constructive outcome of the $\mathrm{X} 1$ and $\mathrm{X} 2$ variable. As the increase in the concentration of X1 variable, concentration of X2 variable, Floating time of Amoxicillin from the Floating in situ formulation is also increasing. X1 concentration of gellan gum have less effect than variable X2 concentration of Calcium chloride because variable X2 have greater effect on floating lag time of prepared gel.

Viscosity $=388.88+126.6 \mathrm{X} 1+40.0 \mathrm{X} 2-4.40 \mathrm{X} 1 \mathrm{X} 2-25.33 \mathrm{X} 1 \mathrm{X} 1$ $+14.66 \mathrm{X} 2 \mathrm{X} 2$ in 3D plot (Figure 5B).

The positive indication of the X1variable chose that the viscosity (cps) is upsurge as for increment the $\mathrm{X} 1$ variable and positive sign of the X2variable demonstrates that the viscosity is also increment respect upsurge the Conc. of calcium chloride variable. From the response surface plot of viscosity, It reveals that the value of viscosity increases with the upsurge of the $\mathrm{X} 1$ variable from -1 to +1 level and increases the X2 variable from -1 to +1 level. Variable $\mathrm{X} 1$ (concentration of gellan gum) have greater effect on viscosity than variable X2 (concentration of calcium chloride).

$\mathrm{Q} 3=33.225-5.798 \mathrm{X} 1-2.273 \mathrm{X} 2+1.21 \mathrm{X} 1 \mathrm{X} 2+2.791 \mathrm{X} 1 \mathrm{X} 1+$ $0.806 \mathrm{X} 2 \mathrm{X} 2$ in $3 \mathrm{D}$ plot (Figure $5 \mathrm{C}$ ).
The coefficient of X1 and X2 both variables bear the negative sign of b1 and b2. Thus, it indicated that increase the concentration of the X1 variable decreases the value of Q3 (\% drug release at $3 \mathrm{hr}$ ), and it also suggests that increase the engagement of the X2 variable decrease the value of Q3 (\%). Response surface plot of Q3 (\%) showed that when the concentration of X1 variable and $\mathrm{X} 2$ variable increases from -1 to +1 level, then the decrease in the percentage drug release from the floating in situ gel of Amoxicillin decreased Q6 = 58.743 - 14.75X1 - 3.085X2 + 1.43X1X2 + 6.46X1X1 - 0.145X2X2 in 3D plot (Figure 5D).

The coefficient of X1 and X2 both variables bear the negative sign of $b 1$ and $b 2$. Thus, it indicated that increase the concentration of the X1 variable decreases the value of Q6 (\% drug release at $6 \mathrm{hr}$ ), and it also suggests that increase the engagement of the X2 variable decrease the value of Q6 (\%). Response surface plot of Q6 (\%) showed that when the concentration of X1 variable and $\mathrm{X} 2$ variable increases from -1 to +1 level, then the decrease in the percentage drug release from the floating in situ gel of Amoxicillin decreased.

$\mathrm{Q} 9=85.75-9.358 \mathrm{X} 1-2.79 \mathrm{X} 2+0.442 \mathrm{X} 1 \mathrm{X} 2-0.695 \mathrm{X} 1 \mathrm{X} 1-$ $1.03 \times 2 X 2$ in 3D plot (Figure 5E).

The Floating time shows, Viscosity $420 \mathrm{Cps}$, Q3 found to be $31.93 \mathrm{~h}$, percent drug release Q 3 was found to be $31.93 \%$, Q6 saw to be $53.93 \%$ at $3 \mathrm{hr}$, and percent drug release Q9 was found $80.37 \%$ at 9 hrs. Therefore, F6 was the ideal formulation from every one of the five responses batch and chose as optimized.

\section{Accelerated stability study}

According to ICH guideline, the optimized formulation (F6) sealed in amber color bottle and kept in humidity chamber maintained $40 \pm 2^{\circ} \mathrm{C} / 75 \pm 5 \% \mathrm{RH}$ for 1 month. At the end of stability studies, sample were analyzed for the drug content, in vitro drug release, $\mathrm{pH}$ and viscosity. Results of the stability studies were presented in table 10 . There was no any change in morphological condition during stability study and also not any significant changes in drug content, in vitro drug release, $\mathrm{pH}$ and viscosity. For stability, it was clearly indicates that there is negligible changes in dug release after stability study as well as also not change in the $\mathrm{pH}$, viscosity and dug content are shown in table 10. 


\begin{tabular}{|l|c|c|c|c|c|c|c|c|c|c|}
\hline & F1 & F2 & F3 & F4 & F5 & F6 & F7 & F8 & F9 \\
\hline Zero Order Model \\
\hline $\mathrm{R}^{2}$ & 0.993 & 0.987 & 0.981 & 0.989 & 0.994 & 0.996 & 0.993 & 0.994 & 0.993 \\
\hline $\mathrm{a}$ & 20.37 & 19.69 & 19.45 & 16.77 & 13.39 & 12.35 & 12.38 & 10.99 & 10.15 \\
\hline $\mathrm{b}$ & 9.77 & 9.05 & 8.23 & 8.10 & 7.66 & 7.14 & 6.79 & 6.70 & 6.63 \\
\hline Higuchi Model \\
\hline $\mathrm{R}^{2}$ & 0.983 & 0.982 & 0.986 & 0.983 & 0.978 & 0.979 & 0.972 & 0.976 & 0.974 \\
\hline $\mathrm{a}$ & -0.54 & 36.82 & -14.76 & -15.96 & -19.28 & -20.25 & -18.26 & -19.50 & -19.97 \\
\hline $\mathrm{b}$ & 37.68 & -14.01 & 35.39 & 34.41 & 33.56 & 32.44 & 30.69 & 30.40 & 30.05 \\
\hline Korsemeyer-Peppas Model \\
\hline $\mathrm{R}^{2}$ & 0.978 & 0.975 & 0.982 & 0.977 & 0.972 & 0.976 & 0.969 & 0.975 & 0.973 \\
\hline $\mathrm{a}$ & 0.566 & -0.582 & -0.633 & -0.653 & -0.702 & -0.737 & -0.734 & -0.774 & -0.794 \\
\hline $\mathrm{n}$ & 0.566 & 0.585 & 0.620 & 0.614 & 0.628 & 0.639 & 0.614 & 0.644 & 0.654 \\
\hline First Order Model & \\
\hline $\mathrm{R}^{2}$ & 0.986 & 0.975 & 0.956 & 0.971 & 0.984 & 0.985 & 0.988 & 0.985 & 0.984 \\
\hline $\mathrm{a}$ & 1.45 & 1.44 & 1.42 & 1.39 & 1.35 & 1.34 & 1.33 & 1.30 & 1.28 \\
\hline $\mathrm{b}$ & 0.07 & 0.066 & 0.063 & 0.064 & 0.062 & 0.058 & 0.057 & 0.059 & 0.060 \\
\hline Hixon Crowell Model & & & & & \\
\hline $\mathrm{R} 2$ & -0.993 & -0.987 & -0.981 & -0.989 & -0.994 & -0.996 & -0.994 & -0.994 & -0.993 \\
\hline $\mathrm{a}$ & 26.54 & 26.76 & 26.84 & 27.74 & 28.86 & 29.21 & 29.20 & 29.66 & 29.94 \\
\hline $\mathrm{b}$ & -3.25 & -3.01 & -2.74 & -2.70 & -2.55 & -2.38 & -2.26 & -2.23 & -2.21 \\
\hline
\end{tabular}

Table 9: Kinetic model data of factorial batches.

\begin{tabular}{|l|c|c|c|c|}
\hline Storage condition & PH & Viscosity (Cps) & Drug Content & Drug release at 12 hrs \\
\hline Initial & 8.22 & 420 & $98.18 \pm 1.89 \%$ & $98.78 \%$ \\
\hline $\begin{array}{l}\text { After } 3 \text { months storage at } 40 \\
\pm 2^{\circ} \mathrm{C} / 75 \pm 5 \% \mathrm{RH}\end{array}$ & 8.19 & 410 & $98.05 \pm 1.20 \%$ & $94.39 \%$ \\
\hline
\end{tabular}

Table 10: Comparison of evaluation parameter after stability study.

\section{Conclusion}

Floating in situ gelling system of Amoxicillin with increased gastric residence time can be formulated using Xanthan gum and Guar gum as a natural polymer. This floating in situ gel is based on the $\mathrm{pH}$ triggered and ion exchange. The optimized formulation $\mathrm{F} 6$ provided sustained in vitro release of drug over an extended period of time up to $12 \mathrm{hrs}$. The drug release from gel structure follows a zero order release. As per the result and discussion the batch F6 is optimized batch which contain drug release $95.78 \%$ up to $12 \mathrm{hr}$, $67.12 \%$ swelling index and show the maximum similarity factor $\left(\mathrm{f}_{2}\right)$
65.09. The optimized formulation can be a competent alternative to conventional oral solid dosage form. The extend the release of amoxicillin can be done by the gelling structure of gellan gum and xanthan gum and hydrophobic nature of $\mathrm{CaCO} 3$ which retard the penetration of water to the gel structure and also so extend the drug release up to $12 \mathrm{hrs}$. As in oral solid dosage form, the dose of Amoxicillin is higher and this drug is generally prescribed in children and elder patient so having difficulty in swallowing problem. That was overcome by formulating $\mathrm{pH}$ triggered and ion exchange floating in situ gel which having drug release of extended period of time. 


\section{Conflict of Interest}

The authors declare that they have no known competing personal and no financial interests that could have appeared to influence the work reported in this paper. The authors alone are responsible for the content.
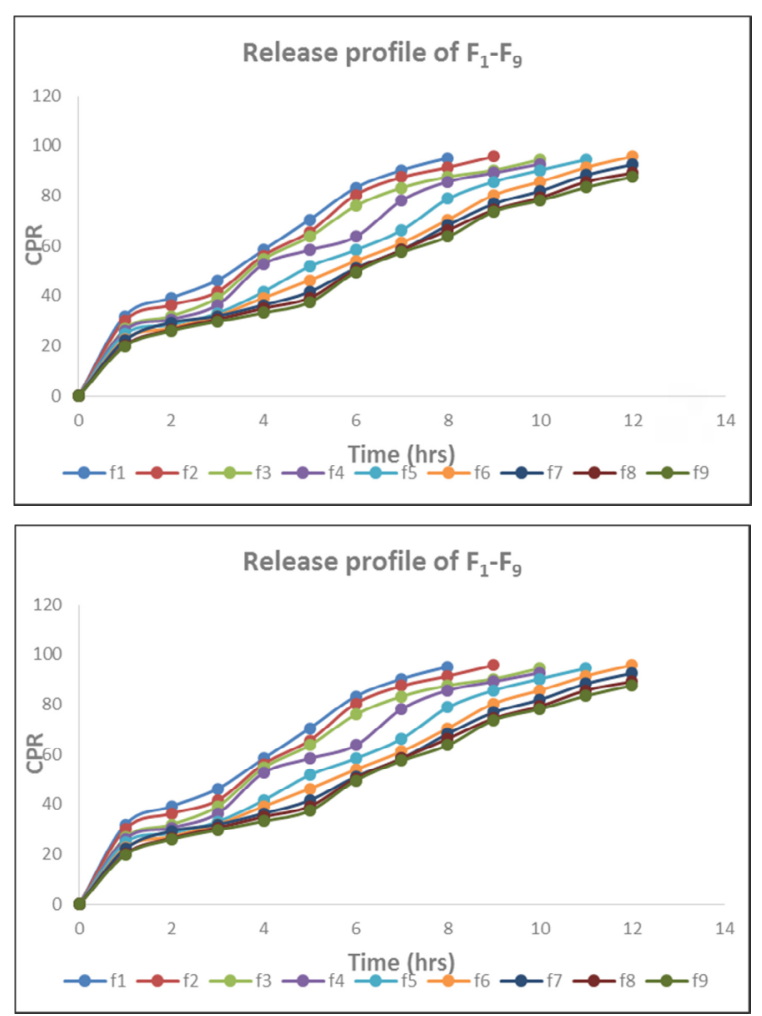

\section{Bibliography}

1. Adebisi A., et al. "Gastro retentive microparticles for drug delivery applications". Journal of Microencapsulation 28 (2011): 689-708.

2. Bhardwaj L., et al. "A Short Review on Gastro Retentive Formulations for Stomach Specific Drug Delivery". African Journal of Basic and Applied Sciences 3 (2011): 300-312.

3. Nayak A, et al. "Gastroretentive drug delivery systems: a review". Asian Journal of Pharmaceutical and Clinical Research 3 (2010): 1-10.

4. Timmermans A., et al. "How well floating dosage do forms float?" International Journal of Pharmaceutics 62 (1990): 207216.
5. Desai SA., et al. "Novel floating controlled release drug delivery system based on a dried gel matrix network". Jamaica, NY; St John's University (1984): 151-163.

6. Vantrappen GR., et al. "The secretory component of interdigestive migratory motor complex in man". Scand Journal of Gastroenterology 14 (1979): 663-667.

7. Doshi N., et al. "In Situ Gel. A novel approach of gastro retentive drug delivery". Asian Journal of Pharmaceutical Sciences 3 (2013): 1-14.

8. Patel MS., et al. "Design and development of gastro retentive floating tablet of fluvastatin sodium". International Journal of Universal Pharmacy and Bio Sciences 3 (2014): 391-421.

9. Shukla S., et al. "A Review On: Recent Advancement of Stomach Specific Floating Drug Delivery". International Journal of Pharmaceutical and Biological Archives 2 (2011): 1561-1568.

10. Sunil K., et al. "Gastro Retentive Drug Delivery System: Features and Facts". International Journal of Research in Pharmaceutical and Biomedical Sciences 3 (2012): 125-130.

11. Talukder R., et al. "Gastroretentive Delivery Systems: A Mini Review". Drug Development and Industrial Pharmacy 30 (2004): 1019-1028.

12. Whitehead L., et al. "Development of a Gastroretentive dosage form”. European Journal of Pharmaceutical Sciences 4 (1996): 182-190.

13. Patel N., et al. "Floating drug delivery system: An innovative acceptable approach in Gastro retentive drug delivery". Asian Journal of Pharmaceutical Research 2 (2012): 7-18.

14. Shep Santosh et al. "Swelling system: A novel approach towards Gastroretentive drug delivery system". Indo-Global Journal of Pharmaceutical Sciences 1 (2011): 234-242.

15. Patel MS., et al. "Application of Quality by Design (QbD) to Develop Dual Release Reconstitutable Oral Suspension (DRROS) of Cefpodoxime Proxetil (CPDP) for Pediatric Patients for the Treatment of Respiratory Tract and Urinary Tract Infections". Journal of Pharmaceutical Innovation (2021).

16. Jivani R., et al. "Development of a Novel Floating In-situ Gelling System for Stomach Specific Drug Delivery of the Narrow Absorption Window Drug Baclofen". Iranian Journal of Pharmaceutical Research 9 (2010): 359-368. 
17. Shailaja P., et al. "Formulation and evaluation of floating in situ gel of ciprofloxacin”. International Journal of Applied Pharmaceutics 11 (2019): 1998.

18. Kranthi Kumar K., et al. "Formulation and evaluation of floating in situ gelling system of losartan potassium". Der Pharmacia Lettre 7 (2015): 98-112.

19. Srilatha KS., et al. "Design of Floating In Situ Gel Of Mucolytic Agent By Cation Induced Gelation Of Natural Polysaccharides". World Journal of Pharmacy and Pharmaceutical Sciences 6 (2017): 2104-2116.

20. Swetha S., et al. "A comprehensive Review on Gastroretentive Drug Delivery Systems". International Journal of Research in Pharmaceutical and Biomedical Sciences 3 (2012): 1285-1293.

21. Gaikwad V., et al "Formulation and evaluation of in situ gel of metoprolol tartrate for nasal delivery". Journal of Pharmacy Research 3 (2010): 788-793.

22. Majithiya R J., et al. "Thermo reversible mucoadhesive gel for Nasal delivery of Sumatriptan". AAPS Pharma Sci Tech 7 (2006): 1-7.

23. Nandgude T., et al. "Formulation and Evaluation of $\mathrm{pH}$ induced in situ nasal gel of salbutamol Sulphate". International Journal of Pharmaceutical Sciences and Nanotechnology 1 (2008): 177182.

24. Supriya S., et al. "Sustain release floating drug delivery system of in situ gelling suspension of Cinnarizine". Journal of Pharmacy Research 1 (2011): 53-64.

25. Prannoy T., et al. "Design and Optimization of Hydrodynamically balanced oral In-situ gel of Lamotrigine". Research Journal of Pharmacy and Technology 13 (2020): 4865-4870.

26. Antony JE., et al. "Formulation and evaluation of stomach specific floating in situ gel of Clarithromycin". International Journal of Pharmaceutical Sciences and Research 11 (2020): 14791487.

27. Esmaeil AH., et al. "Development and Characterization of In Situ Gel Containing Leflunomide as a Gastro-retentive Drug Delivery". International Journal of Pharmaceutical Sciences Review and Research 64 (2020): 8-16.

Volume 5 Issue 9 September 2021

(C) All rights are reserved by Mukesh S Patel., et al.

Citation: Mukesh S Patel., et al. "Design and Development of Novel Floating In Situ Gel of Amoxicillin for the Treatment of Peptic Ulcer Disease Caused by Helicobacter pylori". Acta Scientific Pharmaceutical Sciences 5.9 (2021): 81-93. 